\title{
Os Direitos Humanos e o Estado "natural" de Fundamentação dos Direitos
}

\author{
Human Rights and "natural" State in the Foundation of Rights
}

\author{
André Luiz Olivier da Silva
}

Universidade do Vale do Rio dos Sinos, São Leopoldo - RS, Brasil

\begin{abstract}
Resumo: Neste artigo pretende-se identificar as raízes metafísicas dos projetos de fundamentação dos direitos humanos, que retomam, geneticamente, as doutrinas dos direitos naturais e apelam a um estado individual e anterior à vida em sociedade para justificar direitos que não estão positivados em lei. Com base no modelo contratualista de pensadores como Thomas Hobbes, o presente texto indaga a noção de "natureza" contida por detrás das leis que regulam o estado natural dos homens ao mesmo tempo em que questiona a pressuposição metodológica do indivíduo - o ser humano livre e racional para legitimar a formulação de juízos morais e, principalmente, a enunciação de direitos como os direitos humanos. Pretende-se mostrar, ao final, que não faz sentido abordar os direitos humanos como noção tradicional de "natureza", visto que a natureza humana se constitui a partir de um contexto coletivo, e não do indivíduo embora a discussão contemporânea dos direitos humanos esteja completamente contaminada pela metafísica dos direitos naturais.
\end{abstract}

Palavras-chave: Direitos Humanos. Direitos Naturais. Natureza. Indivíduo.
Absctract: This article intends to identify the metaphysical roots of projects of the foundation of human rights which incorporated genetically the doctrines of natural rights and call for an individual and anterior state to life in society to justify rights that not positivized in law. Based on the contractarian model of thinkers like Thomas Hobbes, the present article investigates the notion of "nature" contained behind the laws governing the natural state of men while questioning the methodological assumption of the individual - the free and rational human being - to legitimize the formulation of moral judgments and, especially, the enunciation of rights as human rights. The paper intended to show, in the end, that it makes no sense to approach human rights from the traditional notion of "nature", as human nature is constituted from a collective context, and not from the individual - although the contemporary discussion about human rights is completely contaminated by the metaphysics of natural rights.

Keywords: Human Rights. Natural Rights. Nature. Individual.

Recebido em: 03/01/2015

Revisado em: 09/05/2015

Aprovado em: 09/06/2015 


\section{Introdução}

Os projetos de fundamentação dos direitos humanos parecem acolher a problemática iluminista do valor absoluto da pessoa humana e o primeiro passo em falso de suas doutrinas é extrair direitos a partir de razões naturais que são pressupostas em um momento individual, no qual o homem é inquirido em uma situação isolada como indivíduo que possui características que são universais, imutáveis e iguais para todos, indiscriminadamente. Esse momento fictício tem suas raízes fixadas na argumentação metafísica dos direitos naturais e é também chamado de "estado de natureza", ou "estado natural", no qual, basicamente, todos os homens são considerados livres e iguais.

O homem passa, então, a ser o foco da investigação, analisado de forma abstrata, como sujeito detentor de interesses privados ou de uma vontade livre; é imaginado e pensado por si próprio, como ser racional e detentor de direitos que lhe são, ou devem ser, "naturalmente" inatos, verificando-se, assim, a evidência e o favoritismo da razão e, por conseguinte, a utopia do progresso da humanidade, quando se conta a história de um homem emancipado, que estaria livre para escolher e tomar decisões. Para auferir direitos "naturais" ao ser humano, essas doutrinas tradicionais que dão coro à tese jusnaturalista terão que pressupor uma posição inicial e hipotética ao indivíduo, anterior à vida social e a priori a toda experiência possível, uma posição que seria capaz de fornecer uma razão prática para universalizar os direitos, tornando os direitos humanos, por assim dizer, em direitos absolutos.

\section{Hobbes e o Estado de Natureza}

Um dos expoentes modernos dessa tese é Thomas Hobbes, cujo pensamento é possível usar para desenhar a caricatura do estado original de natureza, um estado inicial e hipotético ${ }^{1}$ que servirá como condição de possibilidade para a origem dos direitos, um estado no qual a natureza hu-

Segundo afirma Macpherson (1979, p. 31): “O estado de natureza, de Hobbes, tal como é geralmente reconhecido, é uma hipótese lógica, não histórica”. [Hobbes 's state of nature, 
mana é egoísta e toma as suas decisões com base estritamente no interesse pessoal de cada indivíduo. Embora equivocado, Hobbes é, por certo, um pensador de vanguarda, à frente do seu tempo, antecipando as ideias que só ganharão voz com os pensadores libertários do Iluminismo.

O foco no "indivíduo", por exemplo, constitui uma de suas conclusões mais robustas, pois, conforme afirma Macpherson, "O individualismo, como posição teórica básica, começa, no mínimo, há tanto tempo quanto tem Hobbes" (MACPHERSON, 1979, p. 13)2. Nessa posição básica e natural, todos os indivíduos possuem o mesmo direito, embora não haja propriamente sociedade, nem propriedade privada, nem valores morais, pois o homem vive meramente para satisfazer os seus interesses pessoais, sem prestar contas para o que os outros pensam a seu respeito - o que levou Margaret MacDonald (1947, p. 239, tradução nossa) a "[...] tentar entender o que pode ser significado pela afirmação de que existem alguns direitos que os seres humanos estão autorizados, independentemente de suas diferentes relações sociais"3. Trata-se, em resumo, de uma fundamentação utópica dos direitos voltada ao indivíduo por meio do binômio liberdade-igualdade, mais especificamente "[...] um apelo aos valores de liberdade e igualdade entre os homens [...]" (MACDONALD, 1947 , p. 226, tradução nossa $)^{4}$, que se corporificam em leis e direitos de natureza que constituirão a base de justificação dos direitos do homem e do cidadão.

as is generally recognized, is a logical not an historical hypothesis. (MACPHERSON, 1990, p. 20)]

2 Individualism, as a basic theoretical position, starts at least as far back as Hobbes. (MACPHERSON, 1990, p. 1)

${ }^{3}[\ldots]$ to try to understand what can be meant by the assertion that there are some rights to which human beings are entitled independently of their varying social relationships. (MACDONALD, 1947, p. 239)

$4[\ldots]$ an appeal to the values of freedom and equality among men. (MACDONALD, 1947 , p. 226) 


\subsection{O Individualismo Possessivo}

O estado de natureza é uma condição de igualdade para os homens, uma condição que serve, inclusive, como pressuposição da moral ${ }^{5}$, segundo a qual todos os homens são iguais não apenas "quanto às faculdades do corpo e do espírito" (HOBBES, 1979, p. 74)6 $)^{6}$ mas principalmente "quanto à esperança de atingirmos nossos fins" (HOBBES, 1979, p. 74)7. Todos os homens são iguais para usar o seu próprio poder $^{8}$ e, no que tange a esse poder, visam basicamente saciar os seus apetites, alheios ao público e aprisionados ao ímpeto natural do egoísmo9. Todos são iguais porque buscam produzir benefícios ao seu próprio interesse e, para tanto, reagem igualmente à mecânica dos objetos externos e reverberam dentro de si um movimento voluntário, uma tendência, um esforço, "[...] um perpétuo e irrequieto desejo de poder e mais poder, que cessa apenas com a morte" $\left(\right.$ HOBBES, 1979, p. 60) ${ }^{10}$. Todos são iguais porque possuem os mesmos

5 Como se a moral pudesse ser entendida como uma questão de deliberação e escolha racional sobre juízos enunciados sobre o bem e o mal. Segundo esse tipo de concepção, que se pode chamar de "tradicional" da moralidade, a "interioridade" do agente moral é levada em conta em um processo fundamentação teórica dos valores morais. Isto é, a sua capacidade para imputar uma norma a si mesmo é o que pode dar valor aos juízos de bem e mal, e nunca uma norma imposta pelo lado de fora, pelo exterior, como o Estado, por exemplo. É contra essa concepção que o presente artigo visa a romper.

6 [...] in the faculties of body, and mind. (HOBBES, 1996, p. 183)

7 [...] of hope in the attaining of our Ends. (HOBBES, 1996, p. 184)

8 A concepção de direito para Hobbes reduz-se à liberdade, mais especificamente um poder, que é a liberdade concedida ao portador para criar novas relações jurídicas e, portanto, novos direitos.

9 Hobbes se opõe à teoria política de Aristóteles e discorda da premissa de que "o homem é por natureza um animal social” (ARISTÓTELES, 1997, p. 15), conforme afirma Aristóteles. Hobbes também discorda de Aristóteles no que tange à desigualdade natural que haveria entre os homens, segundo o Estagirita. Também discorda da concepção natural de justiça para Aristóteles, visto que a justiça tem a sua origem em uma fonte artificial, que é o contrato. Ao contrário do estagirita, que pressupõe uma comunidade coletiva, a condição humana que vive sem seguir um pacto social, não é mais do que a condição do homem largado à sua individualidade e sujeito às consequências do próprio egoísmo, no qual cada homem é visto sempre como um suspeito, um inimigo, um adversário sanguinário disposto a aniquilar o próximo.

${ }^{10}[\ldots]$ a perpetuall andrestlesse desire of Power after power, that ceaseth onely in Death. (HOBBES, 1996, p. 161) 
interesses subjetivos, o que, para Hobbes, já é suficiente para explicar a origem de direitos inatos e inerentes à sua espécie; direitos como a vida, a liberdade e a propriedade privada, que brotam do interesse que todo animal humano possui quanto à manutenção de sua sobrevivência por meio da liberdade para agir em conformidade com a sua própria razão e da defesa das coisas que se mostram como uma extensão do seu próprio corpo.

Nesse ponto, é possível retomar Locke e sua concepção do direito natural como um direito à propriedade ${ }^{11}$, um direito, diga-se assim, a ser possuído pelos homens, conforme afirma Hart em seu artigo sobre direitos naturais:

Os direitos são normalmente concebidos como possuídos ou apropriados por ou pertencentes a indivíduos, e essas expressões refletem a concepção de regras morais, não só prescrevendo condutas, mas formando um tipo de propriedade moral dos indivíduos para as quais eles estão como indivíduos autorizados [...] (HART, 1955, p. 182 , grifos do autor, tradução nossa) ${ }^{12}$

Essa abordagem dos direitos a partir da propriedade privada instiga Macpherson a denunciar o "individualismo possessivo"13 presente nas

11 Conforme citado anteriormente: "[...] cada homem tem uma propriedade em sua própria pessoa; a esta ninguém tem qualquer direito senão ele mesmo. O trabalho do seu corpo e a obra de suas mãos, pode dizer-se, são propriamente dele" (LOCKE, 1978, p. 45). [...] every man has a property in his own person: this no body has any right to but himself. The labour of his body, and the work of his hands, we may say, are properly his. (LOCKE, 1980, p. 19, grifos do autor)].

12 Rights are typically conceived of as possessed or owned by or belonging to individuals, and these expressions reflect the conception of moral rules as not only prescribing conduct but as forming a kind of moral property of individuals to which they are as individuals entitled; [...] (HART, 1955, p. 182, grifos do autor)

13 A propósito disso, Macpherson denuncia que o "individualismo possessivo" contido nas doutrinas de Hobbes e Locke serve para mostrar a lógica do indivíduo em uma sociedade liberal de mercado: "O paradoxo do individualismo de Hobbes, que começa com indivíduos racionais iguais e demonstra que estes devem se submeter integralmente a um poder exterior a eles mesmos, é um paradoxo não da sua teoria, mas da sociedade de mercado" (MACPHERSON, 1979, p 115). [The paradox of Hobbes's individualism, which starts with equal rational individuals and demonstrates that they must submit themselves wholly to a power outside themselves, is a paradox not of his construction 
teorias modernas do contrato social, como as teorias de Hobbes e Locke, dentre outros pensadores do século XVII e também do contemporâneo. Macpherson afirma:

[...] que as dificuldades da moderna teoria liberal-democrática são mais profundas do que se havia pensado antes: que o individualismo oriundo do século XVII continha a dificuldade central, residindo esta na sua qualidade possessiva. Sua qualidade possessiva se encontra na sua concepção do indivíduo como sendo essencialmente o proprietário da sua própria pessoa e de suas próprias capacidades, nada devendo à sociedade por elas. (MACPHERSON, 1979, p. $15)^{14}$

Segundo a hipótese do estado natural, os indivíduos são, ou devem ser, iguais, pois estão submetidos às mesmas leis e direitos de natureza, vindo a viver igualmente nesse suposto estado, segundo as inclinações e os instintos naturais, que, além de condicioná-los a preservar a própria vida, os obriga a guiar o ímpeto natural por meio da razão. O estado de natureza em Hobbes "[...] era caracterizado por uma estrutura de direitos e deveres morais que era fornecida pela lei natural de Deus [...]" (JONES, 1994, p. 76, tradução nossa) $)^{15}$, de sorte que, a partir desses pressupostos, os direitos serão extraídos da natureza por meio de um procedimento dedutivo, vindo a constituir razões práticas ou morais para promover a autonomia da vontade ou provocar benefícios a interesses.

but of the market society. (MACPHERSON, 1990, p. 106)]. Além do individualismo possessivo de Macpherson, ver também: Ritchie (1998, p. 14).

$14[\ldots]$ that the difficulties of modern liberal-democratic theory lie deeper than had been thought, that the original seventeenth-century individualism contained the central difficulty, which lay in its possessive quality. Its possessive quality is found in its conception of the individual as essentially the proprietor of his own person or capacities, owing nothing to society for them. (MACPHERSON, 1990, p. 3)

15 The state of nature was neither a moral vacuum nor a moral chaos; it was characterized by a structure of moral rights and duties which was supplied by God's natural Law. (JONES, 1994, p. 76) 


\subsection{A Disposição para a Sobrevivência}

No anseio de preservar o próprio interesse e, por conseguinte, a própria vida, manifesta-se no homem uma tendência geral que o estimula e o condiciona naturalmente, de modo a não ter escolha a não ser seguir e se deixar guiar pelo egoísmo, isto é, por leis estabelecidas por sua própria razão - as leis de natureza. O homem é naturalmente agressivo e disposto a matar e destruir o outro porque há uma regra que o obriga a preservar a sua própria existência, mesmo que, para tanto, tenha que agredir o seu semelhante. Todo homem é guiado pela mesma lei de natureza e se sente obrigado aos ditames das leis naturais ao observar os mesmos comandos que lhes obrigam a conservar a própria sobrevivência. A lei de natureza, segundo Hobbes (1979, p. 78):

[...] é um preceito ou regra geral, estabelecido pela razão, mediante o qual se proíbe o homem fazer tudo o que possa destruir sua vida ou privá-lo dos meios necessários para preservá-la, ou omitir aquilo que pense poder contribuir melhor para preservá-la. ${ }^{16}$

No âmbito dessas determinações supostamente naturais, surge o direito de natureza, como é chamado por Hobbes, um direito no qual o homem faz uso apenas de sua própria razão humana, “[...] é a liberdade que cada homem possui de usar seu próprio poder, da maneira que quiser, para a preservação de sua própria natureza [...]" (HOBBES, 1979, p. 78) $)^{17}$ e é justamente a partir desse direito de natureza que surgirão as desigualdades entre os homens, ao ponto de provocar uma guerra que é de todos contra todos, na qual um quer mandar mais do que o outro ao impor sua crença sobre os valores de bem e mal. Embora haja liberdade no estado de natureza, o homem é obrigado a seguir e respeitar os comandos naturais e só consegue exercer a sua liberdade a todas as coisas dentro dos limites das determinações naturais.

$16[\ldots]$ is a Precept, or generall Rule, found out by Reason, by which a man is forbidden to do, that, which is destructive of his life, or taketh away the means of preserving the same; and to omit, that, by which he thinketh it may be best preserved. (HOBBES, 1996, p. 189) 17 [...] is the Liberty each man hath, to use his own power, as he will himselfe, for the preservation of his own Nature; (HOBBES, 1996, p. 189) 
As determinações que brotam da natureza se desdobram em leis naturais, como a primeira lei de natureza, que obriga o homem a preservar a vida e a buscar a paz, mesmo que para tanto tenha que usar os recursos da guerra. A primeira lei de natureza diz o seguinte: "Que todo homem deve esforçar-se pela paz, na medida em que tenha esperança de consegui-la, e caso não a consiga pode procurar e usar todas as ajudas e vantagens da guerra" (HOBBES, 1979, p.78, grifos do autor) ${ }^{18}$. Essa lei é um comando e impõe uma condição ao homem, segundo a qual este deve procurar a paz na mesma proporção em que tenha esperança quanto a sua conquista; e que seja, por certo, benéfica em relação ao seu interesse pessoal. Porém, se isso não for possível ao nosso interesse pessoal, só restará o auxílio de "[...] uma guerra que é de todos os homens contra todos os homens [...]” (HOBBES, 1979, p. 75) ${ }^{19}$, pois, se não é possível a paz social, deve-se, ao menos, almejar a paz pessoal.

Com efeito, a primeira lei de natureza parece implicar uma confusa interpretação que se costuma extrair da teoria de Hobbes, segundo a qual o homem seria avesso, por natureza, à vida em comunidade. Diz Macpherson:

O comportamento humano no modelo de sociedade de Hobbes é, por assim dizer, tão anti-social que, quando Hobbes leva esse comportamento para seu estado hipotético de natureza, nesse contexto, esse comportamento pode com facilidade ser tomado erroneamente como uma afirmativa sobre o comportamento de indivíduos não-sociais. Mas é uma afirmativa sobre o comportamento de indivíduos sociais e civilizados. (MACPHERSON, 1979, p. 33) ${ }^{20}$

\footnotetext{
${ }^{18}$ That every man, ought to endeavour Peace, as farre as he has hope of obtaining it; and when he cannot obtain it, that he may seek, and use, all helps, and advantages of Warre. (HOBBES, 1996, p. 190, grifos do autor)

19 [...] and such a warre, as is of every man, against every man. (HOBBES, 1996, p. 185)

20 The behaviour of men in Hobbes's model of society is, so to speak, so anti-social, that when he carries this behaviour into his hypothetical state of nature, it is there easily mistaken for a statement of the behaviour of non-social men. But it is a statement of the behaviour of social, civilized men. (MACPHERSON, 1990, p. 22)
} 
Não deixa de ser contraditório o homem ingressar na guerra de todos contra todos no anseio de conquistar a paz, mas a guerra, por si só, não é vantajosa, visto que o direito ilimitado mais expõe o homem ao risco da morte do que lhe assegura a própria vida. Assim, todo homem precisa abandonar o direito de natureza - o seu direito a todas as coisas - para conquistar a paz, pois a sua natureza (humana) não caminha na contramão do preceito geral da razão natural e, só quando a guerra se tornar inútil, é aí que não restará opção a não ser vislumbrar a satisfação dos seus interesses pessoais projetados em um estado de paz e confiança recíproca.

\subsection{A Regra de Ouro}

Diante da condição natural estabelecida pela primeira lei, surge uma segunda lei de natureza como a chave para se entender a investigação de Hobbes não somente sobre a política, mas, em especial, sobre a moralidade ${ }^{21}$, agora com base no contrato, visto que apresenta a "regra de ouro" 22 de todo sistema moral normativo ao prescrever que os homens devem entrar em acordo e abrir mão do seu direito a todas as coisas para viver sob a tutela de regras comuns. Em uma situação hipotética como o estado de natureza, a guerra prolongada torna-se inútil, de sorte que só restará ao homem renunciar ao direito de natureza e regular a medida de sua liberdade com base na liberdade que se quer dos outros. A definição da segunda lei de natureza diz o seguinte:

Que um homem concorde, quando outros também o façam, e na medida em que tal considere necessário para a paz e para a defesa de si mesmo, em renunciar a seu direito a todas as coisas, contentando-se, em relação aos outros homens, com a mesma li-

\footnotetext{
${ }^{21}$ O contratualismo moral é uma das correntes contemporâneas que visam a justificação dos direitos por meio de uma convenção não jurídica estabelecida entre os seres humanos que pactuam as regras segundo as quais querem seguir e respeitar.

${ }^{22}$ Tugendhat resume a moral tradicional a partir de uma "regra de ouro": "[...] comportese de tal maneira em relação aos outros como tu desejas que eles se comportem em relação a ti”. (TUGENDHAT, 2003, p. 73)
} 
berdade que aos outros homens permite em relação a si mesmo. (HOBBES, 1979, p. 79, grifos do autor) ${ }^{23}$.

A segunda lei de natureza fomenta a construção artificial do contrato $^{24}$, ao apregoar relações mútuas e recíprocas entre os homens a partir do abandono do direito ilimitado e do estado de guerra. A lei de natureza interfere nas faculdades do espírito, instigando os homens a aderirem a cláusulas pactuadas entre eles mesmos, cláusulas que estabelecem a igualdade de direitos entre os homens. Eles devem abrir mão do seu poder irrestrito, renunciando ao direito de natureza. Devem se preservar em uma situação de igualdade mútua, segundo a qual um respeita o direito dos outros na proporção do direito que lhe cabe. "É esta a lei do Evangelho: Faça aos outros o que queres que te façam a ti. E esta é a lei de todos os homens: Quod tibi fieri non vis, alteri ne feceris [...]" (HOBBES, 1979, p. 79, grifos do autor) ${ }^{25}$, diz Hobbes.

As leis de natureza mostram, então, que, na medida em que o direito de natureza é abandonado, a lei se transforma em uma artificialidade costurada pelos homens na natureza, como um apêndice, uma prótese à natureza, a partir daquilo que Hobbes chamará, mais à frente, lei civil. Nesse processo de artificalização, nasce a terceira lei de natureza,

23 That a man be willing, when others are so too, as farre-forth, as for Peace, and defence of himselfe He shall think it necessary, to lay down this right to all things; and be contented with so much liberty against other men, as he would allow other men against himselfe. (HOBBES, 1996, p. 190, grifos do autor)

24 Embora não se tenha espaço no presente texto para uma abordagem mais detida, não deixa de ser relevante mencionar que o problema pode se tornar ainda maior quando, ao recusar a tese jusnaturalista, cair na sua antítese, a tese do contrato social, segundo a qual os homens, para evitarem as consequências danosas de um estado de natureza, abandonam e renunciam ao direito natural para acordarem, uns com os outros, as cláusulas de um pacto de sobrevivência (dentre tantos outros pactos de que se precisa para viver). Com isso, corre-se o risco de defender o mesmo momento individual de fundamentação anunciado pelas doutrinas dos direitos naturais, conforme pode-se identificar em Rawls e Gauthier, quando defendem, respectivamente, "um véu de ignorância [...]” (RAWLS, 2008, p. 166), ou uma "posição inicial de barganha". (GAUTHIER, 2006, p. 190, tradução nossa)

25 This is that Law of the Gospell; Whatsoever you require that others should do to you, that do ye to them. And that Law of all men, Quod tibi fieri non vis, alteri ne feceris". (HOBBES, p. 1996, 190, grifos do autor) 
que enseja, por sua vez, um encadeamento das outras leis de natureza, unindo a preservação da própria vida e a renúncia ao direito de natureza no ideal contratualista de que os pactos nascem justamente para serem cumpridos. "Que os homens cumpram os pactos que celebrarem [...]" (HOBBES, 1979, p. 86, grifos do autor) ${ }^{26}$, diz a terceira lei de Hobbes, de modo que "Nesta lei de natureza reside a fonte e a origem da justiça [...]" (HOBBES, 1979, p. 86, grifos do autor ${ }^{27}$. A justiça, como um produto do contrato, é uma virtude que surge após a renúncia ao direito a todas as coisas. É uma virtude racional, que garante a justiça na proporção em que considera um indivíduo igual ao outro na medida de sua liberdade. A justiça diz respeito à manutenção contínua da igualdade entre os pactuantes, pois se o outro pode querer alguma coisa de mim, então "eu”, que sou um igual, também o posso em relação a ele. Se o outro pode agir de determinado modo (se tem o "direito" de agir assim), então, "eu" também o posso, pois somos iguais por natureza; "eu" tenho o direito de exigir e devo fazer algo em contrapartida apenas na medida em que os outros também o façam, o que acarreta o equilíbrio da sociedade.

\section{O Estado Ideal de Natureza}

Com base na teoria política de Hobbes, pode-se apontar como dois movimentos básicos de qualquer doutrina fundacionalista dos direitos humanos (1) a pressuposição de um estado individual e natural para fundamentar direitos inatos e inerentes à espécie humana; e (2) pressupor esse estágio natural com o objetivo de explicar e justificar a vida social dos homens, que só seria possível mediante a adesão ou aceitação das cláusulas de um contrato que fixaria as regras de convivência entre os homens.

Nesse ponto, pode-se verificar que as doutrinas dos direitos naturais falham ao pressupor uma condição ideal para o homem, uma condição a

${ }_{26}$ That men performe their Covenants made [...]. (HOBBES, 1996, p. 201, grifos do autor)

27 And in this law of Nature, consisteth the Fountain and Originall of JUSTICE. (HOBBES, 1996, p. 202) 
qual se costuma chamar erroneamente de "natural"28, ao mesmo tempo em que se ignora as autênticas necessidades naturais dos homens. A gênese desse equívoco retoma o século das luzes e a promessa iluminista de emancipação e progresso científico-racional da espécie humana, e, por detrás dessa promessa, reside a doutrina dos direitos naturais, bem como a centralização e a redução da investigação filosófica a uma geografia a respeito do ser humano e dos relevos de sua natureza, deixando escapar uma ambiciosa pretensão em explicar o homem e o seu conhecimento ideal em relação ao mundo que o circunda e em relação as suas ações morais, políticas e jurídicas. Afirma Macpherson (1979, p. 29):

Costuma ser dito, ou suposto, pelos que adotam o ponto de vista tradicional sobre Hobbes, que suas propostas psicológicas tratam o indivíduo como tal, completamente abstraído da sociedade, e que essas propostas contêm tudo o que é necessário para sua dedução da necessidade de um estado soberano. ${ }^{29}$

Nessa posição inicial de individualidade, o ser humano é definido como um indivíduo à parte da sociedade, como uma partícula racional que não sofre os efeitos da pressão social. A partir daí, sim, é possível profetizar que os direitos são a priori e desempenhem funções em conformidade com a natureza livre e racional do ser humano - denunciando o que está em jogo neste ponto, que é a própria noção de moralidade que se desenvolve nos projetos de fundamentação dos direitos humanos. A partir da moralidade, a própria ideia de pessoa ou dignidade humana vincula-

\footnotetext{
28 Afirma Ritchie: "As palavras "natureza” e "natural” são constantemente cogitadas em controvérsia, como se elas resolvessem brigas, enquanto elas só provocam isso a si por sua ambiguidade" (RITCHIE, 1998, p. 20, tradução nossa). [The words "nature" and "natural" are constantly bandied about in controversy as if they settled quarrels, whereas they only provoke them by their ambiguity (RITCHIE, 1998, p. 20)]. Diz Macpherson (1979, p. 36): "Natural', para Hobbes, não é o contrário de social ou civil” (MACPHERSON, 1979, p. 36). ['Natural' for Hobbes is not the opposite of social or civil (MACPHERSON, 1990, p. 25)].

29 It is commonly said or assumed, by those who take the traditional view of Hobbes, that his psychological propositions are about man as such, man completely abstracted from society, and that those propositions contain all that is needed for his deduction of the necessity of the sovereign state. (MACPHERSON, 1990, p. 17)
} 
-se com o individualismo, assim como os direitos humanos e nossas obrigações e responsabilidades, conforme alerta Baier: "A responsabilidade individual e não coletiva é tomada para definir a personalidade, e a separação e autonomia das pessoas torna-se uma doutrina valiosa." (BAIER, 1991, p. 6, tradução nossa) ${ }^{30}$. Em razão disso, é preciso indagar-se sobre quem nos referimos quando se fala em direitos humanos ou em igualdade natural entre os seres humanos, e, mais, é preciso questionar se é possível afirmar a existência de tais direitos sem nos comprometer com uma tese metafísica sobre a pessoa humana ${ }^{31}$.

Com base na ideia de um estado de natureza, o principal equívoco das teorias fundacionalistas dos direitos será considerá-los a partir do indíviduo, quando se concebe o homem em um estágio solitário e individual como portadores de direitos negativos ${ }^{32}$ contra o Estado. $\mathrm{O}$ estado de natureza é a pressuposição racional que impregna a própria definição contemporânea dos direitos humanos e que, por isso mesmo, deve ser vista com muito ceticismo e desconfiança. É a exaltação do indivíduo, isto é, verifica-se, nos programas teóricos dos direitos humanos, uma ênfase muito acentuada dada ao sujeito de direito livre e racional, ao homem sobre o qual o título recai naturalmente e para o qual os direitos desempenham uma função exclusiva.

\footnotetext{
${ }^{30}$ Individual and not collective responsibility is taken to define personhood, and the separateness and autonomy of persons becomes a treasured doctrine (BAIER, 1991, p. 6). 31 Sobre a pessoa humana, ver Araújo (2007, p. 55-77) e Beauchamp (1999, p. 309-320). 32 Tanto para Hobbes, quanto para Locke, os direitos naturais são negativos, conforme esclarece Jones: "O que é geralmente verdadeiro sobre os direitos naturais pensados nos séculos XVII e XVIII é que eram, essencialmente, os direitos fundamentais atribuídos a indivíduos que eram essencialmente de caráter negativo. Eles eram observações para 'se manter fora"” (JONES, 1994, p. 79, tradução nossa). [What is generally true of natural rights thinking of the seventeenth and eighteenth were essentially is that the fundamental rights attributed to individuals were essentially negative in character. They were 'keep out' notices (JONES, 1994, p. 79)].
} 


\section{O Homem como Animal Sociável}

O principal equívoco das doutrinas modernas dos direitos naturais é, então, considerar a natureza humana a partir do indivíduo, visto que os seres humanos estão tão arraigados à vida em sociedade que é impossível considerá-los seres solitários e alheios ao grupo, como se fossem seres livres e autônomos para decidir perante um dilema moral ou mesmo para exercer livremente o seu direito, conforme já apontava Bentham acerca dos direitos naturais. Bentham questionou o espírito libertário e as ideias metafísicas sobre o homem e sua liberdade natural: "Todos os homens nascem livres?" - pergunta ele em tom irônico - "Absurdo e miserável falta de sentido!" (BENTHAM, 1987, p. 50) 33 - é a sua resposta. Contra essa falta de sentido na enunciação dos direitos naturais, Bentham foi um dos primeiros pensadores a elencar severas críticas a esses direitos e a Revolução Francesa, classificando os direitos naturais como disparates retóricos sobre pernas-de-pau:

Direitos naturais é simplesmente um disparate: direitos naturais e imprescritíveis, disparate retórico - disparate sobre palafitas. Mas este disparate retórico termina no velho esforço dos disparates perniciosos: imediatamente uma lista destes pretensos direitos naturais é dada, e estes são assim expressados como a apresentar a visão dos direitos legais. E esses direitos, sejam eles quais forem, não existem, ao que parece, qualquer um deles que qualquer governo possa, em qualquer ocasião, revogar a menor partícula. (BENTHAM, 1987 , p. 53, grifos do autor, tradução nossa) ${ }^{34}$

A ausência de significação para a linguagem dos direitos naturais se deve ao pressuposto metafísico do estado de natureza, quando, ainda

\footnotetext{
33 All men born free? Absurd and miserable nonsense! (BENTHAM, 1987, p. 50)

${ }^{34}$ Natural rights is simple nonsense: natural and imprescriptible rights, rhetorical nonsense - nonsense upon stilts. But this rhetorical nonsense ends in the old strain of mischievous nonsense: for immediately a list of these pretended natural rights is given, and those are so expressed as to present to view legal rights. And of these rights, whatever they are, there is not, it seems, any one of which any government can, upon any occasion whatever, abrogate the smallest particle. (BENTHAM, 1987, p. 53, grifos do autor)
} 
hoje, os programas de direitos humanos afirmam a dignidade da pessoa humana e fundamentam direitos que lhe seriam inerentes em razão de sua humanidade. São programas de fundamentação que, ainda hoje, imaginam um ser humano individual e em sua pureza, esquecendo-se que os homens estão vinculados, desde o seu nascimento, a uma vida social, inseridos em uma comunidade, construindo, juntamente com os demais seres humanos, a linguagem daquilo que se convencionou chamar direitos humanos. A expressão "direitos humanos" é enunciada em conjunto com os demais seres humanos para reivindicar e exigir pretensões que, até segunda ordem, não estariam ligadas a um ordenamento legal-normativo. Segundo Annette Baier, somos, como animais sociáveis, seres falantes que cultivam a construção dos nossos direitos e do ordenamento jurídico:

Cada grupo de seres humanos dentro de qualquer tipo de organização social, isto é, cada grupo de seres humanos, reconhece algo muito parecido com direitos, bem como responsabilidades, anexando outras funções além das funções de fala dentro dessa organização. [...] Porque nós somos animais sociais, e uma destas atividades socialmente aprendidas é falar, temos palavras nomeando as muitas e duradouras funções de algum jogo, e formas de palavras segundo as quais os jogadores podem exigir seus direitos, e segundo as quais outros podem às vezes contestar o conteúdo e o alcance de tais direitos. [...] Porque nós somos animais falantes, [...] e haverá exigências para a extensão de alguns direitos, e disputas sobre a legitimidade da tais exigências. (BAIER, 1994, p. 225, tradução nossa $)^{35}$

35 Every group of human beings with any sort of social organization, that is to say every group of human beings, recognizes something very like rights, as wells as responsabilities, attaching to other roles besides speech roles within that organization. [...] Because we are social animals, one of whose socially learned activities is talking, we have words naming the fairly long-lasting roles that some play, and forms of words in which role players can claim their rights, and in which others can at times contest the content and the scope of these rights. (...) Because we are talking animals, [...] and there will be claims to the extension of some rights, and disputes about the legitimacy of such claims. (BAIER, 1994, p. 225) 
Aliás, a própria noção de indivíduo não passa de uma invenção a partir do meio ambiente no qual está agrupado e inserido o ser humano. $\mathrm{Na}$ medida em que são formuladas novas obrigações, as partes envolvidas vão construindo socialmente um conceito para aquilo que consideram justo ou injusto e, por conseguinte, vão nomeando os direitos e deveres que consideram relevantes para figurar em um sistema legal ou mesmo aqueles direitos essenciais ao ser humano em razão, diga-se assim, de sua própria humanidade - os direitos humanos.

A observação mostra que a enunciação de qualquer direito reside em um contexto comunitário, que revela um ser humano sociável e disposto a cooperar, disposto a se obrigar com outras pessoas, ao contrário do que pensou Hobbes, quando destacou a guerra de todos contra todos. Segundo Baier, em oposição a Hobbes, a linguagem serve tanto para a ajuda e o auxílio mútuo quanto para a discórdia e o desentendimento entre os homens: “[...] a fala nos dá o equivalente moral da harmonia e ajuda mútua, bem como de conflitos e ataque mútuos" (BAIER, 1994, p. 235 , tradução nossa $)^{36}$. O ser humano não é aquele indivíduo autônomo e puro, orientado apenas por seu próprio juízo crítico e movido meramente por seu mais íntimo egoísmo, nem pode ser considerado um ser livre e racional, pois, ao contrário, é completamente dependente dos outros e da comunidade em que habita e onde pode encontrar um sentido para se estruturar como ser humano. Ninguém vive só, afastado e distante do outro, tendo em vista que todos estão inseridos no meio social e ninguém consegue permanecer o tempo todo insensível ao que pensam os demais jogadores do jogo da moral.

A sociabilidade humana é, pois, muito relevante para a nossa investigação filosófica sobre os direitos, pois retira o homem que estava isolado em um estado a priori, colocando-o para fora, expondo-o à sociedade, mostrando-o mais como um animal que vive em grupos do que propriamente um indivíduo. Nesse ponto, as observações de Aristóteles ${ }^{37}$

36 [...] speech gives us the moral equivalent of both accord and mutual help, and also
conflict and mutual attack. (BAIER, 1994, p. 235)
37 Convém retomar a célebre passagem de Aristóteles quando diz que o homem é um
animal sociável que possui a disposição para a fala em conjunto com outros homens.
Diz o Estagirita: "[...] é evidente que o homem, muito mais que a abelha ou outro animal 
parecem estar mais ajustadas ao senso comum do que as filosofias da modernidade de Hobbes, Locke e Rousseau, que mais parecem preocupadas em elaborar uma teoria sobre como os direitos deveriam ser. Mais do que Aristóteles, é preciso adentrar o pano de fundo passional e emotivo de David Hume para entender Hobbes e as doutrinas que vão ao encontro de um estágio individual e natural para explicar a imutável natureza humana.

Hume repudia a tese do estado de natureza, a qual classifica como "[...] a ficção filosófica de um estado de natureza" (HUME, 2004, p. 248 , grifos do autor $)^{38}$ :

Pode-se com razão duvidar de que uma tal condição da natureza humana tenha jamais existido, ou, se existiu, que tenha durado por tanto tempo a ponto de merecer a denominação de um Estado. Os homens nascem necessariamente pelo menos em uma sociedade familiar e são instruídos pelos pais em alguma regra de conduta e comportamento. (HUME, 2004, p. 250, grifo do autor) ${ }^{39}$

A observação sobre a sociabilidade natural dos homens é a intuição de que se precisa para começar a visualizar a saída para a significação moral dos direitos, que será, portanto, mostrar que o sentido dos direitos exigidos a partir de obrigações morais (e não, necessariamente, jurídicas) encontra-se em uma definição informal, compreendendo-os não apenas

gregário, é um animal social. Como costuma-se dizer, a natureza nada faz sem um propósito, e o homem é o único entre os animais que tem o dom da fala. Na verdade, a simples voz pode indicar a dor e o prazer, e outros animais a possuem (sua natureza foi desenvolvida somente até o ponto de ter sensações do que é doloroso ou agradável e externá-las entre si), mas a fala tem a finalidade de indicar o conveniente e o nocivo e, portanto, também o justo e o injusto; a característica específica do homem em comparação com os outros animais é que somente ele tem o sentimento do bem e do mal, do justo e do injusto e de outras qualidades morais, e é a comunidade de seres com tal sentimento que constitui a família e a cidade". (ARISTÓTELES, 1997, p. 15)

${ }^{38}[\ldots]$ the philosophical fiction of the state of natureza. (HUME, p. 189, grifos do autor)

39 Whether such a condition of human nature could ever exist, or if it did, could continue so long as to merit the appellation of a state, may justly be doubted. Men are necessarily born in a family-society, at least; and are trained up by their parents to some rules of conduct and behaviour. (HUME, p. 190, grifo do autor) 
como títulos ao portador, mas, principalmente, como "exigências mútuas e recíprocas" (no sentido de claim-right) que um ser humano reivindica para ou contra o outro no campo das obrigações morais, mesmo quando o portador não está habilitado ao seu exercício. Diz Feinberg: "Seria de melhor alvitre não tentar chegar a uma definição formal, seja de 'direito', seja de 'reivindicação', mas antes usar a idéia de reivindicação numa elucidação informal da idéia do que seja um direito" (FEINBERG, 1974, p. 98 $)^{40}$. Os ditos direitos "morais" constituem-se a partir dessas reivindicações e exigências por direitos, no sentido de que se exige no plano moral - que é por excelência um plano comunitário - que a nossa exigência tenha o peso de um direito positivo ou, por outro lado, que o direito legal tenha força moral para realmente se fazer presente nas relações e obrigações sociais. Essa força "moral" dos direitos, por assim dizer, não pode ser compreendida a partir do indivíduo, porque aí se está retomando o tradicional estado de natureza, ou o sujeito transcendental que coloca lei em si mesmo.

\section{Conclusão}

Os projetos contemporâneos de fundamentação dos direitos humanos cometem, em sua maioria, o mesmo equívoco que as doutrinas modernas dos direitos naturais sempre cometeram: tomam o indivíduo racional como o pressuposto para uma teoria sobre a gênese de direitos que nem positivados estão. A grande dificuldade dessa herança metafísica é o comprometimento dos projetos tradicionais de fundamentação dos direitos com o individualismo oriundo da ideologia iluminista de emancipação do homem, que pode ser imaginado a partir do mitológico estado de natureza. Nesses projetos, o ponto de partida da investigação está viciado por pressupor um momento individual de escolha da vontade ou, então, uma análise pontual dos interesses pessoais do homem, mostrando, por conseguinte, como a investigação pode se perder ao transcender a própria natureza humana com a formulação excêntrica de teses metafísicas como

\footnotetext{
40 We would be better advised not to attempt a formal definition of either "rights" and "claim", but rather to use the idea of a claim in informal elucidation of the idea of a right. (FEINBERG, 1973, p. 64)
} 
aquela que afirma possuir direitos mesmo sem previsão legal atribuindo existência a eles. Mais do que isso, nos projetos de fundamentação, o que se visa é a demonstração da evidência de direitos absolutos e inatos ao ser humano - como se isso realmente fosse possível.

\section{Referências}

ARAÚJO, Marcelo de. O conceito de pessoa na teoria moral contratualista: uma crítica a David Gauthier. Síntese, Belo Horizonte, v. 34, n. 108, p. 55-77, 2007. Disponível em: <http://www.faje.edu.br/ periodicos/index.php/Sintese/article/viewFile/224/410>. Acesso em: 20 mar. 2012.

ARISTÓTELES. Política. Tradução de Mário da Gama Kury. 3. ed. Brasília, DF: UNB, 1997. 321 p.

BAIER, Annette. A Naturalist View of Persons. Proceedings and Addresses of the American Philosophical Association, Newark, v. 65, n. 3, p. 5-17, nov. 1991. Disponível em: <http://www.jstor.org/ stable/3130139>. Acesso em: 24 mar. 2012.

. Moral prejudices: essays on ethics. Cambride, Massachusetts: Harvard University Press, 1994. 369 p.

BEAUCHAMP, Tom L. The failure of theories of personhood. Kennedy institute of ethics journal, v. 9, n. 4, p. 309-320, dez. 1999. Disponível em: <http://muse.jhu.edu/journals/kennedy_institute_of_ethics_journal/ v009/9.4beauchamp.html>. Acesso em: 17 maio 2012.

BENTHAM, Jeremy. Anarchical Fallacies. In: WALDRON, Jeremy.

Nonsense Upon Stilts: Bentham, Burke and Marx on the Rights of Man. London/New York: Methuen, 1987. p. 46-76.

FEINBERG, Joel. Social Philosophy. New Jersey: Englewood Cliffs, NJ, Prentice-Hal, 1973. 126 p.

. Filosofia social. Tradução de Alzira Soares da Rocha e Helena Maria Camacho. Rio de Janeiro: Zahar, 1974. 178 p. 
GAUTHIER, David. Morals by agreement. Oxford: Clarendon Press, 2006.

HART, Herbert Lionel Alphonsus. 1955. Are There Any Natural Rights? The Philosophical Review, Duke University Press, v. 64, n. 2, p. 175191, abr. 1955. Disponível em: <http://www.jstor.org/stable/2182586>. Acesso em: 12 fev. 2012.

HOBBES, Thomas. 1651. Leviatã: ou matéria, forma e poder de um estado eclesiástico e civil. São Paulo: Abril Cultural, 1979. (Os Pensadores).

. Leviathan. Cambrigde: Cambrigde University Press, 1996.

HUME, David. Enquires concerning human understanding and concerning the principles of morals. L.A. Selby-Bigge and P.H. Nidditch. Oxford: Clarendon Press, 2006. 417 p.

. Investigações sobre o entendimento humano e sobre os princípios da moral. Tradução de José Oscar de Almeida Marques. São Paulo: Unesp, 2004. 438 p.

JONES, Peter. Rights: issues in political theory. Hampshire: Palgrave/ Macmillan Press, 1994. 258 p.

LOCKE, John. Second treatise of government. Edited by C. B. Macpherson. Indianapolis/Cambridge: Hackett Publishing Company, 1980. 125 p.

. Segundo tratado sobre o governo. Tradução de E. Jacy Monteiro. São Paulo: Abril Cultural, 1978. p. 31-131. (Os Pensadores) MACDONALD, Margaret. Natural Rights. Proceedings of the Aristotelian Society. New Series, [S.1.], v. 47, p. 225-250, 1946-1947. Disponível em: <http:/www.jstor.org/stable/4544427>. Acesso em: 6 jun. 2012.

MACPHERSON, Crawford Brough. A teoria política do individualism possessive de Hobbes até Locke. Tradução de Nelson Dantas. Rio de Janeiro: Paz e Terra, 1979. 318 p. 
. The political theory of possessive individualism: from Hobbes to Locke. Oxford/New York: Oxford University Press, 1990. 310 p.

RAWLS, John. A theory of justice. Cambridge/Massachusetts: Harvard University Press, 1999. 538 p.

RITCHIE, David George. Natural rights: a criticism of some political and ethical conceptions. Bristol: Thoemmes Press, 1998. 304 p.

TUGENDHAT, Ernst. 1993. Lições sobre ética. 5. ed. Petrópolis: Vozes, 2003.

André Luiz Olivier da Silva é doutor em Filosofia pelo Programa de PósGraduação em Filosofia da Universidade do Vale do Rio dos Sinos - UNISINOS e professor dos Cursos de Graduação em Direito e em Relações Internacionais desta mesma instituição. Bacharel em Filosofia e Direito; Advogado e, atualmente, Coordenador do Curso de Graduação em Direito da Unisinos.

E-mail: aolivierdasilva@yahoo.com.br.

Endereço Profissional: Escola de Direito UNISINOS, Curso de Graduação em Direito, Avenida Unisinos, 950, CEP: 93022-000, São Leopoldo, RS, Brasil. 
